REGARDS

SUR LECONOMIE ALLEMANDE

BULLETIN ECONOMIQUE DU CRAC

\section{Regards sur l'économie allemande}

Bulletin économique du CIRAC

$104 \mid 2012$

Varia

\title{
Joachim Gauck
}

GAUCK J., Freiheit - Ein Plädoyer

\section{OpenEdition}

Journals

Édition électronique

URL : http://journals.openedition.org/rea/4402

DOI : $10.4000 /$ rea.4402

ISBN : 978-2-8218-1286-4

ISSN : 1965-0787

Éditeur

CIRAC

Édition imprimée

Date de publication : 13 avril 2012

ISSN : 1156-8992

Référence électronique

"Joachim Gauck », Regards sur l'économie allemande [En ligne], 104 | avril 2012, mis en ligne le 17 avril 2012, consulté le 22 septembre 2020. URL : http://journals.openedition.org/rea/4402 ; DOI : https:// doi.org/10.4000/rea.4402

Ce document a été généré automatiquement le 22 septembre 2020

(C) CIRAC 


\title{
Joachim Gauck
}

\author{
GAUCK J., Freiheit - Ein Plädoyer
}

\section{RÉFÉRENCE}

GAUCK J., Freiheit - Ein Plädoyer, 2e édition, Kösel, Munich, 2012, 64 p.

1 Cet essai est le fruit du discours de nouvel an tenu en janvier 2011 à l'Evangelische Akademie de Tutzing par Joachim Gauck, ce pasteur de 72 ans originaire de l'ex-RDA qui a été élu $11^{\mathrm{e}}$ président de la République fédérale d'Allemagne en mars 2012. Témoignage saisissant d'une biographie allemande, ces réflexions sont un vibrant plaidoyer en faveur de la liberté, la responsabilité et la tolérance - ces fondements mêmes de la culture de référence (Leitkultur) commune à toutes les démocraties du monde. Ce thème de la liberté et de son corollaire indissociable : la responsabilité de l'individu vis-à-vis de la collectivité, sera au cœur de l'action de J. Gauck en tant que président - autorité morale suprême de la RFA.

Pour cet ancien "habitant » de la RDA qui a toujours refusé de s'en sentir " citoyen ", luttant pour la reconnaissance des droits démocratiques, la notion de Liberté est bien sûr essentielle. Pour ce théologien protestant, la notion de Liberté a une signification plus large et profonde que sa seule acception politique la plus courante : celle de principe au fondement de l'organisation institutionnelle des démocraties. Il ne s'agit pas de ce « désir puissant de liberté et d'absence de tout lien signifiant contrainte " qui surgit à la puberté en chacun d'entre nous et qui reste profondément ancré dans notre être comme la nostalgie d'un univers où nous serions "libres de déterminer nos propres normes". C'est encore moins "l'émancipation» que peut sembler conférer la révolte révolutionnaire, anarchique, mais qui contient toujours en germe la terreur. C'est cela, au contraire, qui fait jaillir la Liberté au sens plein : "quand le rêve et désir de liberté se transmue en l'action de lui donner forme, quand nous avons eu le privilège de vivre ces moments où nous avons pu nous libérer d'une chose mais sans connaître encore la liberté de donner corps à une autre ". C'est de cette transition vers la maturité que naît cette notion de Liberté au sens plein du terme : "c'est cette liberté de l'être adulte que j'appelle la 'responsabilité" ». Vivre pour soi, mais la vie ne prend son sens que quand chacun a une mission à 
remplir, élever un enfant, par exemple, ou participer à la vie collective, toujours en conscience des liens d'interdépendance qui font la nature humaine et celle de la vie en société. Pour ce citoyen de l'Allemagne unie, et rapportées au politique, ces deux faces de la même médaille que sont liberté et responsabilité se traduisent ainsi : «les citoyens sont des gens qui ont des droits civiques et qui ont le pouvoir de les exercer». Face au constat que cette notion de liberté mature semble en perte de vitesse dans une Allemagne où la défense des acquis sociaux semble actuellement l'emporter sur la construction des possibles, et dans une Europe où chacun se crispe sur ses particularismes par peur de perdre son identité en faisant œuvre commune, J. Gauck invite ses concitoyens à affronter l'âge adulte, celui où la responsabilité assumée est l'expression de la liberté. Ce faisant, il livre un message d'espérance: "dans notre aptitude à assumer notre responsabilité réside une promesse qui vaut pour l'individu comme pour le monde entier : nous ne sommes pas condamnés à l'échec ». (ib/sh) 